\title{
Inventing and Devising Movement in the Design of Movement-based Interactive Systems
}

\author{
Lian Loke \\ Faculty of Engineering and Information Technology \\ University of Technology, Sydney \\ PO Box 123, Broadway, NSW AUSTRALIA \\ +61295142696 \\ lian.loke@uts.edu.au
}

\author{
Toni Robertson \\ Faculty of Engineering and Information Technology \\ University of Technology, Sydney \\ PO Box 123, Broadway, NSW AUSTRALIA \\ +61295141966 \\ toni@it.uts.edu.au
}

\begin{abstract}
This paper reports on a study that explored ways of inventing and devising movement for use in the design of movementbased interaction with video-based, motion-sensing technologies. Methods that dancers, trained in movement improvisation and performance-making, used to choreograph movement were examined as sources of potential methods for technology designers. The findings enabled us to develop methods and tools for creating and structuring new movements, based on felt experience and the creative potential of the moving body. These methods and tools contribute to the ongoing development of a design methodology underpinned by the principle of making strange. By making strange, we mean ways of unsettling habitual perceptions and conceptions of the moving body to arrive at fresh appreciations and perspectives for design that are anchored in the sensing, feeling and moving body.
\end{abstract}

\section{Categories and Subject Descriptors}

H5.m. Information interfaces and presentation (e.g., HCI): Miscellaneous.

\section{General Terms}

Documentation, Performance, Design, Human Factors.

\section{Keywords}

Choreography, design methodology, design tool, experiential, interaction design, making strange, method, movement improvisation.

\section{INTRODUCTION}

An emerging area of interaction design is that of movementbased interaction, where interactions with computing technologies are based on the moving body as the source of input (e.g., [12, 24]). The advent of motion-sensing technologies has enabled new kinds of interaction paradigms

OZCHI 2008, December 8-12, 2008, Cairns, QLD, Australia.

Copyright the author(s) and CHISIG.

Additional copies are available at the ACM Digital Library (http://portal.acm.org/dl.cfm) or can be ordered from

CHISIG(secretary@chisig.org)

OZCHI 2008 Proceedings ISBN: 0-9803063-4-5 with a renewed focus on the active, moving body. This in turn has called for new approaches and methods for designing these forms of interaction.

Our research work aims to investigate ways of experiencing, enacting, describing and representing the moving body in the design of movement-based interaction [23, 24, 25, 26, 27, 28]. One strand of investigation focuses on the practices of dance, movement improvisation and choreography as a rich source of potential methods and tools for working with the moving body that could be reapplied in this field of movement-based interaction design. A series of studies was undertaken, with professional dancers and physical performers, to trial and identify a range of methods and tools which enable designers to work with the felt experience and the creative potential of the moving body. These methods and tools were then considered for inclusion in the emerging methodology of making strange, first proposed in [27].

This methodology marks a significant shift in design perspective that calls on designers to re-examine their assumptions about the moving body through a tactic of making strange (or defamiliarising); that is, by unsettling or disrupting habitual perceptions and taken-for-granted conceptions of the moving body through a movement inquiry of our own bodies and the bodies of others. The tactic of making strange is not new and is well established in arts and design practices. Our research is explicitly reframing this familiar tactic of creative design as a governing principle in a methodology directed towards design work anchored in continually renewed bodily understandings of movement experiences.

This notion of "making the familiar strange" is described by the dancer and phenomenologist, Maxine Sheets-Johnstone [35], as a way of reacquainting ourselves with familiar or habitual movements by varying our normal movement patterns and processes. The term defamiliarisation was introduced by Victor Shklovsky, a member of the Russian formalist school of literary theory. In his essay, Art as Technique, published in 1917, he proposes that the method of defamiliarisation is used in art and literature to remove the automatism of perception [34]. For example, turning a picture upside-down interrupts our habitual patterns of perception and allows us to see the composition from a new perspective [10]. Alternatively, we could turn our body upside-down to gain a similar, yet different, change in perspective! In a similar vein, Bell et al. [2] employ a method of making strange, or defamiliarising, understandings of the home in the design of domestic technologies. They use ethnographic techniques, in order to call into question our usual interpretations of everyday objects. The original cultural probes by Gaver et al. [14, 15] work from a premise of making strange 
by provoking people to reflect on their lives in novel ways through Situationist and Surrealist tactics and in turn providing inspirational data for designers.

The development of the methodology of making strange arose from the findings of a series of studies. The first study in the series investigated the act of falling by skilled movers [27]. The act of falling is a specific form of movement that is outside of our everyday realm of movement and has a complex changing form through space and time. We can take the action of falling for the purposes of making strange, moving into unfamiliar territory, stretching our everyday range of movement and experiencing a new, or revitalising an old, movement pattern and pathway. The act of falling is not part of the established movement lexicon in digital praxis. This makes it open for investigation, unlike gestural actions such as pointing and grasping, which are well known and researched in humancomputer interaction and virtual reality. Physical demonstrations and interviews were conducted with dancers and physical performers to examine the process and experience of falling. Analysis of the raw data from two perspectives - an experiential perspective and an external or machine perspective - generated a range of descriptions and representations of the moving body.

From this initial study of falling we identified a range of methods and tools that formed the beginnings of our methodology of making strange. The methodology in its initial form contained two key areas: ways of accessing the experiential, moving body and ways of describing and representing movement. On reflection a missing part of the methodology was methods for inventing and devising (or choreographing) movement. New forms of movement and new meanings for these movements are envisaged in future interactive systems and spaces. Some of these methods can be employed in the service of making strange with the moving body, as they provide ways of experiencing and exploring movement outside of the familiar or everyday.

The second study in the series, the focus of this paper, addresses this gap in the methodology. Methods that dancers, trained in movement improvisation and performance-making, used to choreograph movement were examined as sources of potential methods for technology designers. The results of this second study were then examined for potential expansion or refinement of the methodology. The other parts of the methodology not covered in this paper include methods and tools for describing and representing movement, primarily from the observational and machine perspectives, and tools for mapping between the experiential perspective and the machine perspective.

The paper is structured as follows. A summary of related research is given to situate our contribution and provide background to the paper. The study of inventing and devising movement is presented in detail. The findings of the study are then used to extend the developing methodology of making strange. We conclude by suggesting how this methodology can be useful in the design of movement-based interaction with video-based, motion-sensing technologies.

\section{BACKGROUND}

A growing trend in human-computer interaction $(\mathrm{HCI})$ is the application of creative design approaches and methods for exploring design concepts and opening up new spaces for design. Examples include cultural probes [14, 15], extreme characters and interaction relabelling for the design of aesthetic interactions with products [8] and multi-disciplinary design methods under the moniker of the Interactive Thread [29]. The performative interactions of $[11,18]$ and the Focus Troupes of [31] draw on performance-based techniques from theatre including dramatisation, improvisation, role-playing and props.

Researchers in $\mathrm{HCI}$, product design and participatory design have developed a variety of different approaches to designing for, and from, the moving body. Common to their approaches is a shared commitment to grounding understandings of their design domain in their own experiences as sensing, feeling and moving beings and to designing interactive systems from experiences and explorations of movement, rather than from a technological starting point. They have developed specific methods for acquiring bodily understandings of gestures and movements and for communicating about movement through movement $[5,7,9,17,19]$.

A number of researchers are exploring the use of the moving body as a design material, together with developing a design sensibility for working with movement, by drawing on firstperson methodologies from dance and somatics $[7,17,20,21$, $23,30,32,33]$. For these researchers the body-in-motion and its felt experience are the generative source and medium for exploration of dynamic, qualitative concepts for design and the ultimate test of successful engagement with interactive systems, products and spaces. What is lacking in the literature, however, is a range of specific techniques and exercises for accessing and directing attention to different aspects of movement and for acquiring movement skills for working with parameters of space, time, etc. It is these very techniques and exercises that designers need to practice with their own bodies in order to work productively and creatively with the moving body as a design material and to develop a design sensibility. The results presented in this paper address this issue, as described below.

\section{THE STUDY}

The primary aim of the study was to explore ways of inventing and devising movement for use in the design of movementbased interaction, by drawing on the practices of dancers and physical performers trained in movement improvisation and performance-making. A secondary aim of the study was to explore forms of representing the choreographed movements and the corresponding interactive treatments of the movements. The focus of this paper is on the primary aim, although the secondary aim significantly influenced the kind of data we wanted and in turn, the research design.

Two workshops were conducted with dancers who had previously participated in the study of falling and were trained in movement improvisation and performance-making. The first workshop was conducted with two dancers, Esther and Michael (pseudonyms), to explore the use of falling as input to an interactive space built on motion-sensing technologies.

The first finding from the first workshop was that techniques for generating improvised movement, such as scoring, could be useful in design exploration and enactment of movements for use in interactive systems. Scoring provides a structure for generating and devising movement based on a set of elements or parameters that can be varied as desired. For example, a simple score consists of three elements of walking, standing still and moving in place. Other parameters of speed, duration, 
timing, scale, focus, use of space, and so on, can be added to the score.

The second finding from the first workshop proved critical to the success of the study. The session failed to produce adequate data for exploring interactive treatments of choreographed movements and the corresponding representations of both the movements and the machine interpretations of the movements. On reflection, the session was set up with too few contextual constraints for the dancers to work within, resulting in the production of dislocated fragments of choreographed movements that lacked coherency and significance. This highlighted the need for a specific and well-defined context or domain within which to generate meaningful movements, with regards to the framing of the activity of inventing and devising movement. This reinforced an earlier finding from a study of movements performed in interaction with Sony Playstation2 Eyetoy $^{\mathrm{TM}}$ games, where the context of the games enabled people to perform meaningful movements [25]. Others have emphasised this need for specific and well-defined restrictions to successfully produce meaningful work. Examples include devised theatre practitioner, Bert van Dijk [36], and Brandt and Grunnet's [4] use of Keith Johnstone's theatre improvisation techniques and role-playing in future product design. As a consequence of this finding, an iteration in research design was conducted to try and get the required data, by placing the research within a well-defined domain.

In order to focus specifically on the relation between choreographed movements and machine interpretations of those movements, a constructed design situation was set up involving the initial development of a choreographic work sited within a video-based, motion-sensing interactive space. The system would need to accommodate a range of human movement, from the ordinary, everyday movements of people to the skilled, choreographed movements of dancers. We were particularly interested in the act of falling and how it could be utilised both choreographically and interactively in these kinds of spaces. The same motivations hold for using falling, as given in the earlier study of falling [27].

A second workshop was held with two dancers, Esther and Gloria (pseudonyms). Two researchers, including the first author, also took part in the workshop.

\subsection{The Divine and Bodily Experience}

The finding from the first workshop demanded the need for a specific and well-defined context or domain within which to generate meaningful movements. To this end the design of the interactive space was structured and constrained in the following ways. The default physical and technical configuration for the space was a four-screen projection system and an overhead video camera for sensing the activity in the space. A series of four acts was conceived that would address different kinds of movement, different combinations of audience and performers and different models of interaction between people and the system. One of the four acts is described in Table 1. Act 2 was assigned to Gloria and Act 3 to Esther.

A theme was chosen for the work of The Divine and Bodily Experience. It was selected for being an abundant resource of bodily and movement experiences engendered by existing religious and cultural practices, considered to be culturally shared and familiar to people. The meanings and motivations for bodily actions, movements and postures could be informed by such practices. It also provided a richer, recognised context for acts of falling. It was hoped that this theme would provide sufficient inspiration for choreography of movement and imaginings of what the interactive, immersive space might look, sound and feel like. In a choreographic sense, there was room for artistic interpretation of the theme, rather than a stereotypical representation or reproduction of ritual movements. The point here is that the particular theme chosen is not significant in itself, but for its ability to generate meaningful movements and for its accessibility to performers.

\section{Table 1. Description of Act 3, Swooning in Ecstasy}

This act is a continuation of Act 2, but now more heightened and dramatic acts of falling are introduced that symbolise succumbing to or uniting with the divine forces. As with Act 2, the system will respond to certain configurations or trajectories of performers and to specific movements or gestures, by changing the visual, sound and lighting output in some way. The thematic content is concerned with heightened, transformative states.

An inspirational resource kit was given to the two dancers in advance of the workshop to assist with briefing, guiding and inspiring the choreographic work they were to bring to the workshop. The kit provided a set of thematic constraints and various resources for inspiring and documenting the choreographic work. However they were free to interpret the thematic content and bring in their own interests and training. The specific religious practice of Buddhism was chosen as the thematic content for the kit, as much for the ready availability of images and texts, as for well-established traditions of cultivating transcendence through the body. The kit contained image tiles, evocative texts, movement description cards, floor plan of space (A3 size), CD of music/sound samples and written description of the acts and scenarios. There are some similarities to cultural probes $[14,15]$ in the format and underlying artistic exchange, although the kit is used here in a more participatory fashion.

A set of initial scenarios was provided to seed the design work and to give some indication of the possible behaviour of the system in response to the activity of people in the space (a selection is presented in Table 2). These fragmentary scenarios would be reworked into a coherent account of the activity of the performers, audience and system after the workshop to reflect the ideas and decisions made during the workshop.

This use of scenarios continues and extends earlier research into the production and use of movement-oriented scenarios for exploring the interactivity of interactive, immersive spaces based on motion-sensing technologies [26, 28]. These movement-oriented scenarios focus on the activity and movement of people (typically users as audience) in the space, described in terms appropriate to the kind of space under design. Here we turn the focus from audience to performers. This enables us to examine more complex and choreographed kinds of movement, compared to the everyday.

Table 2. Scenario fragments - initial

Scenario Act 2. Four performers enter the space. They move slowly amongst the audience, repeatedly performing a Qi-Gong 
like swaying movement. Sounds of chanting emanate from the space. The projected images are now from inside a temple.

Scenario Act 3. Two of the performers begin to whirl on the spot. This triggers an operatic voice. The other two performers are invoking the divine from above. Then they swoon and spiral to the floor, or slowly collapse, and remain there. This triggers a change in the projected images. They slowly rise again, using an image of being pulled up by a string from the crown of the head.

In the workshop, the dancers presented and explained how they used the kit. Each dancer then demonstrated and led the other workshop participants in performing the choreographed movements. The workshop concluded with the group discussing and documenting possible interactive treatments of the choreographed movements. The activities of the workshop were filmed for later analysis.

The analysis of the data generated from the workshop is now described as follows. The development of each dancer's movement ideas and choreography is described, including their use of the inspirational resource kit for inspiration and documentation. Their different ways of choreographing movement were carefully examined to identify methods for inventing and devising movement that could be useful for technology designers.

\subsection{Using the kit}

Esther worked with most of the resources from the kit - the evocative texts, the image tiles, the movement description cards, but not the music (she preferred to add music later, as she felt that music can dictate the choreography too strongly). She began by selecting a few lines of text that triggered some kind of movement idea. She documented her movement choreography ideas on the large sheet of cardboard by using the image tiles and textual descriptions to build a thread or sequence. Interestingly she placed all of it around the outside of the square representing the physical space of the system, and did not use this space. A photograph of her use of the kit is in Figure 1.

Here are selected quotations describing her way of working with the kit,

"It was selecting one of those (evocative texts) that I felt something that gave me a movement impulse. Even the word 'suspense' ... I started to think about suspension, and that was something from the last session that I was working with, that sense of teetering and suspension. We live in a constant state of suspense and ambiguity. So from suspense, I thought of acts of suspension, and trying to relate that to my act, which is Swooning in Ecstasy. I started to think about how something would build into some kind of swooning, or ecstatic state. I then started to look at the tiles, and I guess the images - I didn't choose them aesthetically, it was more about whether I had some kind of feeling state from them."

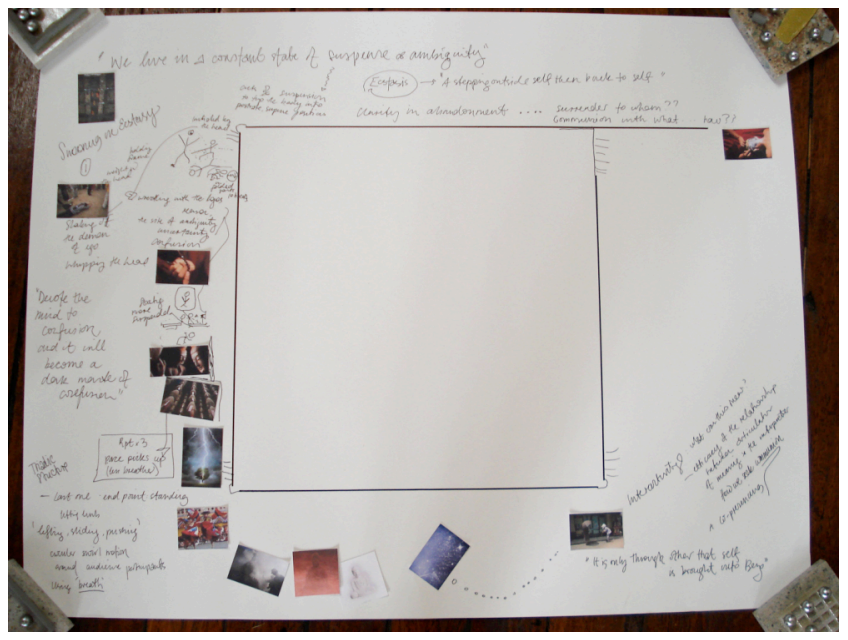

Figure 1. Documentation of choreographic ideas using the kit by Esther

"I started to think about what swooning meant for me, in a way. I came up with this 'clarity in abandonment' - how that can also be translated in a movement sense. But then I started to move into things like, the Heideggerian idea of 'ecstasis', which is the Greek, stepping outside yourself, and back to self. It's his idea of temporality. And so that gave me a movement, kinaesthetic sensation about this stepping out, stepping in. But also the clarity in abandonment, so having a movement form that still has a form, still quite grounded, but the sense of surrender and abandonment that happens in swooning."

Looking at her documentation, we can see that it is organised around the images and concepts. The focus is on the body movement arising from these images and concepts. A series of stick figures depicts the sequence of movements in a choreographic phrase, noting the temporal development in terms of pace and repetition.

Gloria did not use the kit for choreographing after the initial inspection of the contents. Instead she chose to develop her movement/choreographic ideas from the movement practice of Qi Gong. She made brief notes in a small book. At the beginning of the session she transferred these ideas onto the large sheet of cardboard and found some image tiles that resonated with her ideas. A photograph of her use of the kit is given in Figure 2.

Here is a selected quotation describing her way of working with the kit,

"Well that was sort of interesting. I did it the way I usually do things. Having seen this initially and liked it, not knowing how I was going to use it, and did it my usual way. And then, it actually fits. It's good, all these pictures which I wasn't actually thinking about when I constructed it, well actually that one fits that, and that one fits that. So it sort of worked in retrospect."

In response to a question of what was her normal process of choreography, 


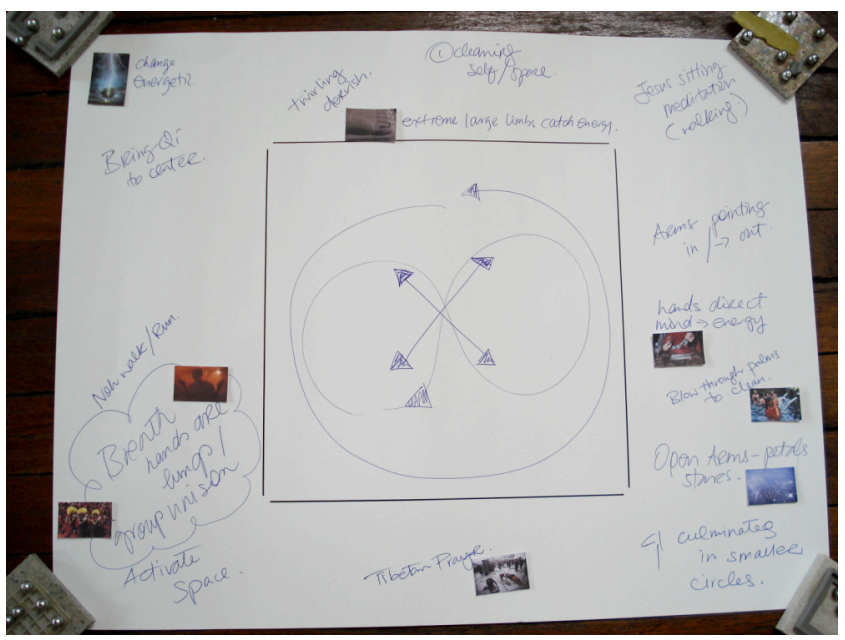

Figure 2. Documentation of choreographic ideas using the kit by Gloria

"Just to do things. Feel it, do it and then scribble it out in a notebook. But more to actually feel what it means, as opposed to write it down. But then this (the images in the kit) actually made it quite easy to understand."

Looking at Gloria's documentation using the kit in Figure 2, we can see the ideas she had for structuring space and generating movement. There are strong spatial shapes and directions for moving in trajectories through space, for example, circle, figure-eight and radiating out from centre to corners. The body/movement ideas are predominantly expressed as a combination of gestures, energy (Qi) flow and imagery. The image of a woman bathing with her hands held up to her face in a prayer position is annotated with the text "blow through palms to clean". The image of a star-studded sky is annotated with the text of "open arms - petals, stars". These two examples indicate the type of gesture and imagery to be used in performing these movements. As yet there is no specific sequencing or development of these movement ideas into a definitive choreography.

The dancers' quite different ways of working with the kit brought out the multiple functions of an artefact in design - in this case, the set of image tiles played a dual role: an inspirational role in terms of provoking and generating ideas, and a documentary role in terms of providing an alternative form of articulating or presenting an idea. The movement/choreographic ideas are expressed or articulated through a combination of text, sketching and images. This documentation using the kit can then act as a resource for returning to the original ideas as conceived by the dancers.

\subsection{Methods for Inventing and Devising Movement}

A closer examination of Esther's process of using the kit reveals a method of inventing and devising movement that begins from multiple entry points: a piece of text or a word can invoke a movement impulse or inspire thinking on related or associated concepts; images can evoke a feeling state. A concept can give rise to a movement or kinaesthetic sensation that can then be developed choreographically.

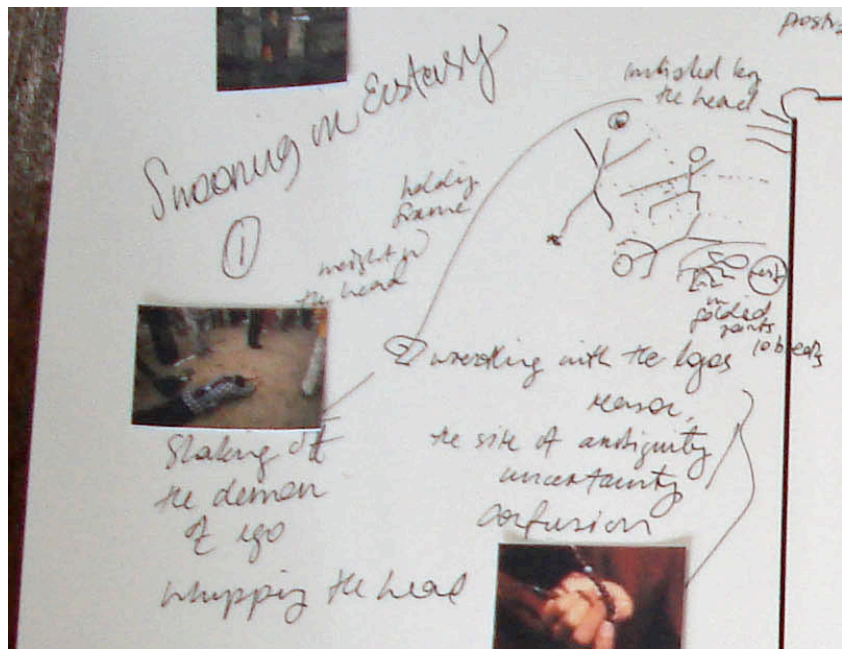

Figure 3. Close-up of Esther's documentation using the kit

A specific example illustrated in Figure 3 begins with an image of a woman lying prostrate on the ground. The annotated text by Esther reads "slaking of the demon of ego, whipping the head". The next reference to the head is "wrestling with the logos", which then leads to the stick figures depicting a sequence of positions, where the movement transitions are initiated with the head. In this example, there is a clear connection between the original image, the concepts and the movement choreography.

An examination of Gloria's process of choreographing movement (from observations and video footage) reveals another method for devising movement. She begins with a movement phrase taken from a traditional movement form. She then experiments with variations of the movement phrase through actual movement improvisation. She uses imagery and energy qualities to inform the character and shape of the movement. She uses her intuitive sense of feeling things in the body to decide what works for this choreography. For example, with the "blow through palms to clean" gesture, she begins by breathing into the hands in prayer position, focusing on the rhythm of the breath. She plays with the hands expressing the expansion and contraction of the lungs, varying the scale and speed of the hand movements, until a certain arrangement of gestures and body movements is reached. The point of crystallisation of the choreography is not explicitly explained by her other than as a confirmation felt in-the-body through the integrated acts of sensing, feeling and moving.

Gloria's method of devising movement highlights a crucial aspect of working with the moving body, which is to have an understanding of movement 'in-the-body'. Movement possibilities are experienced and developed through the sensing, feeling and moving body. Rather than simply observing the movements of another, the imperative here is for designers to explore and perform the movement ideas, so that they can acquire an understanding of movement that is rooted in their own felt, bodily knowing.

The results of the study were examined for potential extension and refinement of the methodology of making strange. The current form of the methodology is presented below, with an emphasis on the methods for inventing, devising, investigating and re-enacting movement. 


\section{METHODOLOGY OF MAKING STRANGE}

The methodology of making strange is underpinned by a commitment to designing movement-based interaction from an experience of movement. It stems from a phenomenologicallyinspired inquiry into the moving body, where we investigate our own experiences of movement, together with the experiences of others. It contains a set of methods and tools for exploring, experiencing, generating, inventing, describing and representing movement in the design of movement-based interaction. This methodology enables designers to shift between the different perspectives of the first-person experiential, the observational and the machine, depending on which method/tool is being employed.

One of the main principles of the methodology of making strange is a return to the active, experiencing body. Many of the methods are concerned with acquiring direct experience of the moving body in various design activities. The following sections describe the activities of inventing and devising movement, investigating movement and re-enacting movement, as these activities all involve the active, moving body and enable direct experience of movements.

\subsection{Inventing and devising movement}

The methods and tools presented here are for inventing and devising new forms of movement. These new movements may be improvised, choreographed, emergent or structured movement systems. Methods for inventing and devising movement overlap in part with the methods for investigating movement, presented in section 4.2.

Ways of inventing and devising movement can be broadly split into two categories: (1) working with parameters and qualities of movement and (2) through inspiration from concepts, text, images and other means of intellectual thinking that is then translated into movement. A design imperative for generating meaningful movements is the importance of providing a specific and well-defined context or domain, as it gives structure and meaning to movements.

\subsubsection{Working with parameters and qualities of movement}

The activity of inventing and devising new movements can begin with the sensing, feeling and moving body. The method of scoring used in practices of movement improvisation provides a structure for generating and devising movement based on a set of elements or parameters that can be varied as desired. For example, a simple score consists of three elements; walking, standing still and squatting. Parameters or constraints related to speed, duration, timing, scale, focus, use of space, etc., can be added to the score. Scores can be used for improvising movement whilst exploring movement ideas for interaction or for generation and enactment of movement in user testing. The order and timing of these elements is not prescribed and is improvised during actual performance of the score. More complex scores can be devised incorporating more parameters and constraints on the movement, as well as interactions with other people, objects and the environment.

Another approach is to begin with a traditional movement form or gesture. This form or gesture can then be choreographically developed by varying the parameters and qualities of movement, using techniques described in sections 4.2.1 and 4.2.4.

\subsubsection{From words/concepts/images}

Methods for inventing and devising movement can begin with a word, concept or image. These can generate or inspire a movement impulse, kinaesthetic sensation, a particular way of moving, spatial arrangements of the body in relation to itself, other bodies and the body in space and so on.

\subsection{Investigating movement}

This area of the methodology is concerned with accessing the experiential, moving body directly with one's own body through movement inquiry underpinned by the principle of making strange. One can begin an inquiry into the potential movement possibilities and felt sensations of one's own body by performing a familiar movement differently or by performing an unfamiliar movement. We can select physically challenging or unorthodox movements, such as falling, for investigation. The movement inquiry can be deepened through repetition of movements to consciously access in-the-moment sensations and process. The methods and techniques presented here provide ways of exploring and improvising with the moving body to cultivate a refined awareness and ability of the sensing, feeling and moving body. They form but a small part of an established repertoire of movement improvisation techniques from dance and movement practices $[3,22]$. The bodily understandings of movement gained from these techniques provide a foundation for the activity of describing and representing movement. And just as importantly, the creative potential of the experiential, moving body is opened up and available for use in the design process.

\subsubsection{Kinetic variations of speed, scale and direction}

One can perform a movement with kinetic variations of speed, scale and direction to produce different dynamics and qualities of movement [35]. For example, you can swing your arm to and fro very slowly and smoothly or with a jagged stutter. The focus here is on the relation between the movement and the felt sensation of movement.

\subsubsection{Exploring internal and external perception}

The sensing of the external environment is performed predominantly with the visual and tactile organs of perception, the eyes and the skin, respectively. The sensing of the dynamics of our body-in-motion and the internal environment of the body is governed by the kinaesthetic sense. There are simple exercises to heighten awareness of the different senses and understand how they influence our ability to perform various kinds of movements. For example, exploring the act of balancing on one leg with the eyes open and then with the eyes closed. With the eyes open, our vision assists with balancing and stabilising ourselves in space. With the eyes closed, a more internal understanding of what is involved in balancing on one leg opens up. The field of somatics focuses particularly on cultivating awareness of movements and the corresponding felt sensations and relationships in the body $[1,6,13,16]$.

\subsubsection{Finding pathways}

We can experiment with finding pathways into a pattern or form of movement by varying the source of initiation of movement 
from different parts of the body. For example, you can walk through space with the right hip or the knees or the back of the head leading. The use of the head-as-a-limb in Cohen's BodyMind Centering is thought to open up the imagination [6, p.133]. Here the head is actively exploring and leading the body through space. It is not rigidly held or overly yielding to gravity.

\subsubsection{Imagery}

A different kind of technique uses imagery to shape body movements and generate distinct movement qualities, such as 'like a heavy stone' or 'like a floating feather'. The image can be localised to a part of the body or it can be extended beyond the physical body. For example, you might move your leg as if it contained a viscous fluid. Or you might imagine that a long string was pulling you up by the crown of the head towards the heavens.

\subsection{Re-enacting movement}

Re-enactment of scripted, choreographed or improvised movement provides actual movement for use in testing and evaluation of the design of interactive systems. It enables design reflection and refinement that is anchored in a bodily understanding of what it is like to act, move, perceive and respond in interaction with such systems. It provides designers with first-hand experiential data on the interactional viability of particular forms and patterns of movement. Felt, bodily experience can be garnered of architectural qualities of interactive spaces such as the sense of scale, enclosure and spatial arrangement. The visual and sonic outputs of the system can be experienced kinaesthetically as well as visually and aurally. The effects of interaction between people on their actions, movements and perception can be gauged. Enactment of scripted, choreographed or improvised movement grounds the imaginings of user behaviour and experience in actual bodies.

We have worked with a range of design representations of movement which can be used for re-enactment, including movement-oriented scenarios, spatial movement schemas in Labanotation floor plans, movement scores and directions for choreographed movement.

\section{CONCLUSION}

The assumption behind our research is that the design of movement-based interaction begins with the experiential, moving body. We have presented here the findings from a study of trained dancers that explored ways of inventing and devising movement for use in the design of movement-based interaction with video-based, motion-sensing technologies. The main outcome of the study, with regard to this paper, was the identification of methods the dancers used to choreograph movements. Critical to the methods for generating movements was the need for a specific context or domain in which to situate the movements.

The findings from the study enabled us to further develop the methodology of making strange that is intended to act as a resource to orient and support designers of movement-based interaction within emerging motion-sensing technologies. This methodology marks a significant shift in design perspective that calls on designers to re-examine their assumptions about the moving body through a tactic of making strange; that is by unsettling or disrupting habitual perceptions and taken-forgranted conceptions of the moving body through a movement inquiry of our own bodies and the bodies of others.

Specifically we developed the area of inventing and devising movement to extend the existing methodology of making strange that had already contained two primary areas: investigating movement and its felt experience and describing and representing movement from the experiential and machine perspectives. This means that the methodology now contains methods and tools for generating new movements that are also grounded in the sensing, feeling and moving body. This is an area of the methodology that can be substantially expanded in the future by continuing to work with choreographers and movement improvisation practitioners.

In future movement-based interactive spaces, we will need different kinds of movements with meanings that are, as yet, unthought because the contexts in which they will be performed have not yet been developed let alone understood and inhabited. We suggest that the tools and techniques provided in the methodology of making strange can assist designers in making movement and interaction choices that are grounded in the sensing, feeling and moving body. Grounding interaction design choices in the activities and abilities of real living bodies can help ensure that emerging motion-sensing interactive technologies are both usable and useful - in the broadest, most human-centred understandings of these terms.

\section{REFERENCES}

1. Bartenieff, I. and Lewis, D. Body Movement: Coping with the Environment. Gordon and Breach Science Publishers, New York, 1980.

2. Bell, G., Blythe, M. and Sengers, P. Making by Making Strange: Defamiliarization and the Design of Domestic Technologies, ACM Trans. Computer-Human Interaction, 12, 2 (June 2005), 149-173.

3. Blom, L.A. and Chaplin, L.T. The Moment of Movement: Dance Improvisation. University of Pittsburgh Press, Pittsburgh, 1988.

4. Brandt, E. and Grunnet, C. Evoking the future: drama and props in user centered design. In Proc. Participatory Design Conference. CPSR (2000).

5. Buur, J., Jensen, M. V. and Djajadiningrat, T. Hands-only scenarios and video action walls: Novel methods for tangible user interaction design. In Proc. 2004 Conference on Designing Interactive Systems: Processes, Practices, Methods, and Techniques, ACM Press (2004), 185-192.

6. Cohen, B. B. Sensing, Feeling, and Action. Contact Editions, Northampton, MA, 1993.

7. Djajadiningrat, J. P., Matthews, B. and Stienstra, M. Easy doesn't do it: Skill and expression in tangible aesthetics. Journal of Personal and Ubiquitous Computing 11, 8 (2007), 657-676.

8. Djajadiningrat, J. P., Gaver, W. W. and Fres, J. W. Interaction relabelling and extreme characters: methods for exploring aesthetic interactions. In DIS '00: Proc. 3rd conference on Designing interactive systems (2000). ACM, New York, NY, USA, 66-71.

9. Donovan, J. and Brereton, M. Meaning in movement: A gestural design game. In Proc. PDC2004 Artful Integration: 
Interweaving Media, Materials and Practices, vol. 2, Toronto, Canada (2004), 163-166.

10. Edwards, B. Drawing on the Right Side of the Brain. Fontana, London, 1979.

11. Ehn, P., Binder, T., Eriksen, M.A., Jacucci, G., Kuutti, K., Linde, P., de Michelis, G., Niedenthal, S., Petterson, B., Rumpfhuber, A. and Wagner, I. Opening the digital box for design work: Supporting performative interactions, using inspirational materials and configuring of place. The Disappearing Computer, LNCS 4500. Springer-Verlag, Berlin, Heidelberg (2007), 50-76.

12. Feijs, L., Kyffin, S. and Young, B. (eds.) Proceedings of DeSForM 2006, 2nd International Workshop on Design and Semantics of Form and Movement, Eindhoven, The Netherlands (2006).

13. Feldenkrais, M. Awareness Through Movement. HarperCollins, 1972.

14. Gaver, W.W., Dunne, A. and Pacenti, E. Cultural probes. interactions vi, 1 (1999), 21-29.

15. Gaver, W.W., Boucher, A., Pennington, S. and Walker, B. Cultural probes and the value of uncertainty. interactions $x i$, 5 (2004), 53-56.

16. Hanna, T. Somatics: Reawakening the Mind's Control of Movement, Flexibility, and Health. Da Capo Press, 1988.

17. Hummels, C., Overbeeke, C.J. and Klooster, S. Move to get moved: a search for methods, tools and knowledge to design for expressive and rich movement-based interaction. In Journal of Personal and Ubiquitous Computing 11, 8 (2007), 677-690.

18. Jacucci, C., Jacucci, G., Wagner, I. and Psik, T. A manifesto for the performative development of ubiquitous media. In CC '05: Proc. 4th Decennial Conference on Critical Computing. ACM, New York, NY, USA (2005), 19-28.

19. Jensen, M. V., Buur, J. and Djajadiningrat, T. Designing the user actions in tangible interaction. In CC '05: Proc. 4th Decennial Conference on Critical Computing, ACM, New York, NY, USA (2005), 9-18.

20. Jensen, M. V. A physical approach to tangible interaction design. In TEI '07: Proc. 1 st International Conference on Tangible and Embedded Interaction, ACM, New York, NY, USA (2007), 241-244.

21. Klooster, S. and Overbeeke, C. J. Designing products as an integral part of choreography of interaction: The product's form as an integral part of movement. In Proc. DeSForM 2005, 1st International Workshop on Design and Semantics of Form and Movement, Newcastle, UK (2005), 23-35.

22. Laban, R. The Mastery of Movement. Play Inc., Boston, 3rd edition, 1971.

23. Larssen, A. T., Robertson, T. and Edwards, J. Experiential bodily knowing as a design (sens)-ability in interaction design. In Proc. DeSForM 2007, $3^{\text {rd }}$ European Conference on Design and Semantics of Form and Movement, Newcastle-upon-Tyne, UK (2007).

24. Larssen, A. T., Robertson, T., Loke, L. and Edwards, J. (eds.) Journal of Personal and Ubiquitous Computing, Special issue on Movement-based interaction 11, 8 (2007).

25. Loke, L., Larssen, A. T. and Robertson, T. Labanotation for design of movement-based interaction. In Proc. Second Australasian Conference on Interactive Entertainment. ACM International Conference Proceeding Series, 123 (2005). Creativity \& Cognition Studios Press, Sydney, 113120.

26. Loke, L., Robertson, T. and Mansfield, T. Moving bodies, social selves: Movement-oriented personas and scenarios. In Proc. OZCHI 2005. Canberra, Australia (2005).

27. Loke, L. and Robertson, T. Making strange with the falling body in interactive technology design. In Proc. DeSForM $2007,3^{\text {rd }}$ European Conference on Design and Semantics of Form and Movement, Newcastle-upon-Tyne, UK (2007).

28. Loke, L. and Robertson, T. Design representations of moving bodies for interactive, motion-sensing works. International Journal of Human Computer Studies (in press).

29. Mackay, W.E. The interactive thread: Exploring methods for multi-disciplinary design. In Proc. DIS2004. ACM, Cambridge, Massachusetts, USA (2004).

30. Moen, J. From hand-held to body-worn: Embodied experiences of the design and use of a wearable movementbased interaction concept. In Proc. 1st International Conference on Tangible and Embedded Interaction, ACM Press, New York (2007), 251-258.

31. Sato, S. and Salvador, T. Methods \& tools: Playacting and focus troupes: Theatre techniques for creating quick, intense, immersive, and engaging focus group sessions. interactions, vi, 5 (1999), 35-41.

32. Schiphorst, T. and Andersen, K. Between bodies: Using experience modeling to create gestural protocols for physiological data transfer. In Proc. CHI 2004 Fringe, ACM Press (2004).

33. Schiphorst, T. Really, really small: The palpability of the invisible. In C\&C '07: Proc. 6th ACM SIGCHI Conference on Creativity \& Cognition, ACM, New York, NY, USA (2007), 7-16.

34. Shklovsky, V. Art as Technique. Modern Criticism and Theory: A Reader. Harlow, Longman, 2000.

35. Sheets-Johnstone, M. The Primacy of Movement. John Benjamins Publishing Company, Amsterdam Philadelphia, 1999

36. Van Dijk, B. Devised Theatre: A Devising Model. 2006 [online: www.theater-tools.com] 